\title{
FÖRVISNINGARNA AV FINLÄNDARE TILL SIBIRIEN UNDER AUTONOMIN OCH DE FÖRVISADE I SIBIRIEN'
}

\author{
Av Alpo Juntunen
}

\section{Inledning}

Då Finland var en del av det svenska riket var fångvården ordnad enligt svenskt mönster. Fångarna förvarades i kalla och mörka slotts- eller andra kronobyggnaders källare runt om i riket. Till förvisningsstraff kunde man dömas endast för politiska brott. Förvisningen hade sålunda ingen egentlig betydelse för fångvården. Under Gustav III:s regeringsperiod (1771-1792) mildrades strafflagen i enlighet med upplysningstidens anda, och under Gustav IV Adolfs tid (1792-1809) påbörjades en fängelsereform. Reformen avbröts dock av storpolitiska skäl. ${ }^{2}$ Enligt det avtal som Napoleon och Alexander I slöt i Tilsit år 1807 skulle Ryssland tvinga Sverige med i en blockad riktad mot kontinenten. Då förhandlingarna i detta syfte inte ledde till resultat, utbröd krig mellan Sverige och Ryssland år 1808.

I Ryssland infördes förvisning till Sibirien i lagstiftningen under tsar Aleksi Mihailovits̀ tid år 1649. Senare ökade förvisningens betydelse som strafform; såväl en hög politiker som en underhavande som hamnat $\mathrm{i}$ onåd hos sin godsägare kunde hamna i Sibirien. Först genom upplysningsidéernas inverkan började man fästa uppmärksamhet vid de förvisades ställning, men reformer rörande de förvisade inleddes först av M. Speranski under 1820-talet. ${ }^{3}$

\section{Förvisningens uppkomst, grunder och mål $i$ Finland}

Under det krig som utbröt mellan Ryssland och Sverige erövrade Ryssland hela Finland, vars nya statsrättsliga ställning ordnades på Borgå lantdag år 1809. Av Finland bildades ett autonomt storfurstendöme, som styrdes av Rysslands kejsare. Alexander I försäkrade också att han skulle vidmakthålla landets tidigare lagar och rättigheter.

På lantdagen diskuterade ständerna också talrika Finlands inre ärenden. Då man skärskådade den allmänna oron och uppgången i brottsligheten, som förorsakats av kriget, föreslog prosten Johan Sundwall i prästståndet att tjuvarna skulle förvisas till Sibirien. Därifrån skulle brottslingarna inte kunna återvända till Finland, och i Sibirien skulle de kunna börja ett nytt liv fria från 
gamla belastningar. Ständerna godkände dock inte förslaget, då man ansåg att det innebar en lagändring. Ständerna fick nämligen inte diskutera lagändringar. ${ }^{4}$

Då trångboddheten i fängelserna blev allt svårare togs förvisningsförslaget upp på nytt. Generalguvernör Fabian Steinheil förfrågade sig år 1813 hos lagarnas högsta övervakare i landet, prokurator Mathias Calonius huruvida det var nödvändigt att höra ständernas åsikt ifall finländska brottslingar skulle komma att förvisas till Sibirien. I sitt svar godkände Calonius förvisningen. Enligt honom var det endast frågan om en tillämpning av straff och inte om en lagändring. ${ }^{5}$

Behandlingen av ärendet försenades dock av kriget mot Napoleon och den därpå följande Wien-kongressen. Rikets förvaltning normaliserades först i slutet av år 1816. I början av följande år föreslog man för kejsaren att finländare skulle förvisas, ${ }^{6}$ men förslaget godkändes inte, eftersom förvisningsärendena som bäst var föremål för omorganisation i Ryssland.

Det dröjde inte länge innan den allmänpolitiska situationen igen inverkade på ärendets behandling. I sitt trontal i Warszawa 27.2.1818 framhöll Alexander I, att Ryssland inom kort skulle få en friare statsförfattning och att man i Finland skulle kunna sammankalla lantdagen. ${ }^{7}$ Av denna orsak började man förbereda ärenden, vilka skulle komma att behandlas vid lantdagen. Ett sådant ärende var förvisningen av brottslingar till Sibirien. Ledande personer inom stånden tillfrågades om sin åsikt beträffande en förvisning av finländare. ${ }^{8}$ Åsikterna var motstridiga och gav inte en klar bild av det avgörande, som eventuellt skulle göras på lantdagen. Lantdagen sammankallades likväl inte. Frågan om förvisning av finländare förblev därför tillsvidare olöst.

Inom Finlands förvaltning skedde betydande förändringar på 1820-talet. I slutet av år 1823 blev generallöjtnant A. A. Zakrevski generalguvernör. Efter att ha bekantat sig med landets fängelseförhållanden konstaterede han att fångarnas förhållanden var dåliga, nästan outhärdliga, och ansåg dem vara en kvarleva från det gamla svenska systemet. Enligt honom borde reformer genomföras enligt ryska förebilder. ${ }^{9}$ I Ryssland hade man börjat reformera förvisningssystemet med stöd av förordningar, som avgivits år $1822 .{ }^{10}$

Större betydelse för Finlands ställning än bytet av generalguvernör hade likväl Alexander I:s död i slutet av år 1825 och Nikolaj I:s tronbestigning. Zakrevski var sedan tidigare Nikolajs förtrogna och han började genast driva på ett avgörande av talrika ärenden rörande Finland. ${ }^{11}$ Förslaget om förvisning av finländare till Sibirien gav den nya härskaren en möjlighet av att framstå som en nådig härskare. Man beslöt att endast sådana män, som benådats från dödsstraff skulle förvisas till Sibirien. Förordningen om förvisning av från dödsstraff benådade till tvångsarbete på livstid i Sibirien gavs 21.4.1826. ${ }^{12}$

Frågan om förvisning även av kvinnor framfördes år 1847 från ett oväntat 
håll. I början av år 1847 föredrogs för kejsaren nådesansökningar beträffande kvinnor, vilka dömts till livstidsstraff på spinnhuset i Villmanstrand. Kejsaren förfrågade sig om det skulle vara möjligt att till Sibirien förvisa kvinnor, som för grova brott dömts till fängelse på livstid. Till en början motsatte sig Finlands senat under ledningen av C. W. Trapp förvisning av kvinnor, eftersom man ansåg att Sibirien var en olämplig plats för kvinnliga fångar. Efter att generalguvernör A. S. Mens̀ikov detaljerat hade presenterat Rysslands förvisningssystem, godkände senaten förvisning av dödsdömda kvinnor. Däremot gav senaten inte sitt bifall till en mer vidsträckt tillämpning av förvisningen enligt ryska förebilder. ${ }^{13}$

Förvisningen av kvinnor betydde en ökning av förvisningarna. Då de dödsdömda kvinnorna fick sina fängelsestraff omvandlade till förvisning, anhöll en grupp kvinnor från fängelset i Villmanstrand, vilka dömts till fängelse, om tillstånd att få emigrera till Sibirien. Likaså ansökte en grupp manliga fångar, som dömts till Sveaborg, om tillstånd att få emigrera. Bägge ansökningarna bifölls, men fängelsemyndigheterna hade rätt att välja ut dem som skulle överföras till Sibirien. Fångar, som var i dålig kondition och som i övrigt var olämpliga för en deportation, tilläts inte emigrera. Emigrationstillståndet utvidgades till att gälla även personer, vilka för upprepat lösdriveri dömts till fängelse. ${ }^{14}$

Varje fånge, såväl sådan som befriats från dödsstraff som sådana som fängslats för lösdriveri ansökte av kejsaren om omvandling av sitt straff till förvisning. Kejsaren biföll eller förkastade ansökningarna $i$ enlighet med de finska myndigheternas föredragning. I denna praxis skedde en förändring år 1856. Från denna tidpunkt fördrogs för kejsaren endast sådana ansökningar, som hade godkänts av de finska myndigheterna. ${ }^{15}$

\section{De från Finland till Sibirien förvisade}

De förvisade fördelade sig på tre grupper:

1) Under åren 1826-1888 förvisades till tvångsarbete 806 män och 93 kvinnor.

2) Under åren 1848-1886 förvisades, på basen av ansökning, till kolonister 1201 män och 111 kvinnor, vilka dömts till fängelse.

3) Under åren 1848-1886 förvisades, på basen av ansökning, till kolonister 852 män och 258 kvinnor, vilka fängslats för upprepat ḷösdriveri.

Alla som benådats från dödsstraff förvisades inte. Under åren 1826-1888 dömdes 1694 personer till döden. Av dem förvisades 899, eller endast $53 \%$. Nära hälften av de dödsdömda utstod alltså sitt straff i hemlandets fängelser. ${ }^{16}$ Störst var antalet förvisade från Wasa län, där våldsbrottsligheten ökade på 
1850- och 1860-talet. Från år 1871 minskade antalet förvisningar, eftersom då trädde i kraft en lag, vilken begränsade dödsstraffet till de allra grövsta och för samhället mest skadliga brotten. Av männen hade 789 gjort sig skyldiga till brott mot liv. Endast 8 män hade gjort sig skyldiga till andra brott, som var belagda med dödsstraff. Av kvinnorna hade 22, d.v.s. 26,7 \%, gjort sig skyldiga till mord eller dråp. Betydligt fler eller 71 kvinnor d.v.s. 76,3 \% hade gjort sig skyldiga till barnamord. Barnamordet var på 1800-talet ett typiskt kvinnobrott. Dessa gärningar berodde på de ogifta mödrarnas svåra situation. Kyrkan fördömde utomäktenskapliga förbindelser. En kvinna som fött ett oäkta barn fick ett dåligt rykte. Hennes möjligheter att försörja barnet var dåliga. Då befolkningen snabbt ökade på 1800-talet och då näringslivet stagnerade försämrades försörjningsmöjligheterna ytterligare. Barnamördarna var vanligtvis döttrar till torpare, backstugusittare och självägande bönder. De hade blivit gravida under den tid de tjänade som pigor och försökte dölja detta för sitt husfolk. En piga hade inte pengar eller tid att sköta om sitt barn. En som fött ett oäkta barn kunde förlora sin arbetsplats. ${ }^{17}$

Majoriteten av de som dömts till fängelse och som deporterades till kolonister, hörde även till de lägre samhällsklasserna. Denna grupp fördelade sig jämt på hela landet.

Det var lagstiftningen som var orsaken till att lösdrivargruppen ökade. Legohjonsförordningen av år 1805 föreskrev att envar, som inte hade laga utkomst, arbetsplats eller stadigvarande bostad, skulle söka tjänst hos annan. Ifall så inte skedde, ansågs personen ifråga vara lösdrivare och vederbörande skulle överföras till kronans arbetsinrättning. Där skulle han tillbringa minst ett halvt år, men om personen visade sig vara lat eller vanartig, förlängdes tiden i inrättningen. Han befriades först när han hade bättrat sig. Det nya reglementet för arbetsinrättningar av år 1839 och förordningen om laga försvar och behandling av lösdrivare av år 1852, betydde att situationen skärptes vid en tidpunkt, då befolkningen snabbt ökade. Fängelserna och arbetsinrättningarna fylldes av människor, som inte hade gjort sig skyldiga till något egentlig brott. Först år 1883 gavs en för tidens förhållanden lämpad lösdrivarförordning, som från lösdrivarnas skara avlägsnade alla dem, som var tvunga att flytta på grund av omständigheterna eller som hörde under fattighjälpen. ${ }^{18}$ Alla lösdrivare som deporterades till Sibirien hade varit i arbetsinrättning för upprepat lösdriveri. Ur fångrullorna framgår det, att deras väg hade gått från en arbetsinrättning till en annen. Genom att söka sig till Sibirien ville de komma bort från de svåra förhållandena och från den ständiga cirkulationen ut och in i fängelserna.

Under åren 1826-1888 förvisades sammanlagt 3321 personer från Finland. Av dessa var 2859 män $(86 \%)$ och 462 kvinnor (24\%). 899 personer $(27 \%)$ sändes till tvångsarbete och $2422(73 \%)$ förvisades till kolonister. Den främsta 
avsikten med förvisningen av personer som benådats från dödsstraff var att bestraffa och att bli av med brottslingen. Att förvisas till kolonist hade framförallt fångvårdsmässig betydelse. På detta sätt kunde man lätta på trängseln i fängelserna.

\section{De förvisade i Sibirien}

Enligt den statliga autonomin var alla finländare undersåtar till kejsaren-storfursten och medborgare i Finland, men de var inte medborgare i Ryssland. De som förvisades till Sibirien förlorade däremot sitt finländska medborgarskap och underställdes fullständigt ryska lagar och myndigheter. De förvisade överlämnades i Viborg till de ryska myndigheterna, som transporterade dem till Sibirien.

Efter en lång, mödosam fotvandring som tog ca ett och ett halvt år anlände finländarna till Tobolsk. Genom förvisningsförordningen av år 1822 hade man där grundat ett centralt verk för förvisningsärenden. Genom detta verk gick samtliga förvisade och där beslöts om deras placeringsorter. Enligt 1822 års förordning sändes personer, som gjort sig skyldiga till grova brott och som dömts till livstids tvångsarbete, till gruvorna och fabrikerna (manufakturerna). Samtliga som förvisats från Finland och som hade benådats från dödsstraff, hörde till denna grupp. Strafftiden för en person som dömts till livstids tvångsarbete var 20 år. Efter detta fick han avlägsna sig från straffanstalten och bosätta sig som kolonist utanför den anvisade arbetsplatsen. ${ }^{19}$ I 1845 års förordning preciserades utplaceringen i tvångsarbete. ${ }^{20}$ Tvångsarbetaren kunde komma i en 1) gruva, 2) fästning eller 3) fabrik. De som dömts till gruvorna skulle placeras i gruvområdet i Nerts̀insk i Östra Sibirien. Saltkokerier och brännvinsbrännerier blev de huvudsakliga utplaceringsställena för personer, som hade dömts till fabriksarbete. Huvuddelen av de finska männen hamnade i Nerts̀insk-området, medan kvinnorna åter utplacerades runtom i Östra-Sibirien. Genom att bestämma speciella prövotider för tvångsarbetarna, under vilka de måste avtjäna den hårdaste delen av sitt straff, underlättade man deras möjligheter att bli kolonister. Efter klanderfritt utstånden prövotid blev de s.k. förtroendefångar. Först då den i domen utsatta strafftiden hade gått till ända blev de fria. Efter strafftidens utgång fick de bosätta sig som kolonister i Sibirien. Straffet för dem som hade dömts till tvångsarbete var trots lättnaderna så strängt, att mycket få uppnådde ställningen av kolonist efter avtjänat straff.

Majoriteten av de förvisade var dock sådana som hade sänts ut som kolonister. De placerades som nybyggare främst i Västra Sibirien, söder om sextionde breddgraden, antingen i närheten av gammal bosättning eller i byar som hade grundats enkom för dem. Till en början placerades finnarna i byn Ryżkova som grundats av ingermanländska kolonister år 1803. Ankomsten av 
kriminella element förorsakade oro, och en del av ingermanländarna övergav sin by. De grundade år 1847 nya kolonier i Bugene och Bojarka i oblastet Omsk. För att lugna förhållandena grundade den lutherska kyrkan i Ryssland egna kolonier för de förvisade både i Östra och Västra Sibirien. I Östra Sibirien grundades kolonin i Minusinsk, där finländarna från år 1857 hade sin egen by, Verhne Sujetuk. I Västra Sibirien fanns Om-kolonin, där byn Helsingfors blev finnarnas placeringsort från år 1863. Alla finländare placerades visserligen inte i dessa kolonier, ty en del av dem, som förvisats från Finland, spriddes över Sibirien. ${ }^{21}$

Den lutherska kyrkan i Ryssland sörjde också för de deporterades religiösa och kulturella behov. För detta arbete bad man om hjälp också från Finland, och år 1864 sändes en finsk präst och kateket till Verhne Sujetuk. ${ }^{22}$ På 1880-talet konstaterades att huvuddelen av finnarna bodde i Västra Sibirien, och den finska prästens placeringsort blev Omsk medan kateketen stannade i Verhne Sujetuk. Prästens och katekens verksamhetsförutsättningar var dåliga. Församlingsborna bodde på ett vidsträckt område, lika stort som Europa. Därför måste prästen och kateketen hela tiden befinna sig på resande fot. Det mest omfattande arbetet för finnarna i Sibirien giordes av prosten Johannes Granö och kateketen P. E. Lindholm, som i årtionden utförde sitt arbete i Sibirien.

Liksom också övriga deporterade anpassade sig även finländarna dåligt till tillvaron som kolonister. Regeringen skapade inte tillräckliga ekonomiska förutsättningar för kolonisationsverksamheten, och då de förvisade, med ett fătal undantag, var alldeles medellösa, var det nästan omöjligt att grunda ett eget hushåll. Beträffande finnarna förelåg ännu de svårigheter som förorsakades av ett främmande språk och en främmande kultur. Endast en fjärdedel av dem som hade deporterats som kolonister bodde stadigvarande på förvisningsorten. ${ }^{23}$

Arbetet på guldvaskerierna i Östra Sibirien erbjöd de förvisade goda inkomster, men som arbetsplatser var vaskerierna temporära och i samband med dem uppstod inte någon fast finsk bosättning. De stora avstånden i Sibirien och polisens maktlöshet erbjöd dem som $\mathrm{i}$ hemlandet hade fört ett kriminellt och lösdrivande liv bättre möjligheter än i Finland att fortsätta med sin gamla livsstil.

Finnarnas andel av hela Sibiriens befolkning var nästan betydelselös. Endast i de socknar, där de lutherska kolonierna var belägna, uppgick finländarnas andel av befolkningen till mellan två och sju procent. ${ }^{24}$

\section{Rymningarna fiån Sibirien}

Ett viktigt motiv för förvisningarna var föreställningen, att de deporterade inte kunde rymma från sin fjärran straffort tillbaka till Finland. Förhoppningarna 
om att ingen skulle återvända från Sibirien gick inte $i$ uppfyllelse. I den organisation, som svarade för förvisningarna fanns många svagheter. Tjänstemän och vakter som arbetade i straffanstalterna var inte alltid vuxna för sin uppgift. Därför var rymningar mycket vanliga. Folket ansåg det inte ens vara ett brott att avlägsna sig från kolonierna. T.o.m. från de egentliga straffanstalterna kunde ibland $80 \%$ av fångarna vara på rymmarstråt. För rymlingarna var Sibiriens natur och de långa avstånden ett värre hot än fasttagarna. Många rymlingar gick vilse och dukade under i ödemarken. ${ }^{25}$ En del lyckades dock komma ända till Finland, där de uppdagades. Varje rymling, som fasttogs och återsändes till Sibirien väckte sensation, som tidningarna skrev om. I och med dessa skriverier förlorade Sibirien så småningom sitt rykte som en rymningssäker bestraffningsort. Vid ingången av 1880-talet ansåg man, att förvisningen var lättare än ett fängelsestraff.

\section{Upphävandet av förvisningarna}

Först på 1860-talet, då det statliga livet blev friare i Finland inleddes en offentlig diskussion om förvisningarna. Tidsperiodens mest betydande finska statsman J. V. Snellman inledde diskussionen. Han motsatte sig inte deportationerna som sådana, men ville sätta brottslingarna att dika ut myrarna i hemlandet i stället för att uppodla Sibiriens ödemarker. ${ }^{26}$

Samtidigt diskuterade man en reform av strafflagen. Det ansågs nödvändigt att överlag lindra straffen. Förvisning till Sibirien ansågs vara en dålig strafform, som borde ersättas med något annat straff. Man ansåg också att förvisningen var olaglig, eftersom ständerna inte hade godkänt den. Senaten föreslog likväl inte för regenten att man skulle upphöra med förvisningarna, eftersom det inte var passande att uttala sig om det sätt, som kejsaren ville använda för att utöva den benådningsrätt, som tillkom honom enligt lag. ${ }^{27}$

Som en akut orsak till förvisningarna hade man ansett trängseln i Finlands fängelser och deras dåliga skick. Eftersom förvisningarna i någon mån lättade upp utrymmesbristen, förverkligades under en lång tid inte några egentliga reformer i straffanstalterna. Förutsättningen för en reform av strafflagen var likväl en fängelsereform. I enlighet med väst-europeiska förebilder utarbetades på 1860-talet under universitetssekreteraren och juristen Adolf Grotenfelts ledning en omfattande plan för reformer av fängelserna. Från år 1872 beviljade lantdagen årligen ett betydande anslag för fängelsernas förnyelse. Då man år 1892 ansåg att byggnadsprogrammet till sina huvuddelar var förverkligat, hade man för byggnadsarbetena använt ca 7,6 milj. mark. Vid denna tidpunkt fanns det flera fångplatser i fängelserna än făngar i medeltal. ${ }^{28}$

Med början på 1860-talet hade Finland på tre årtionden övergått till ett fängelsesystem som motsvarade internationella krav. Man hade nått en 
situation, som hade varit på tal redan under Borgå lantdag. Finland förmådde nu själv svara för sina brottslingar.

Även i Ryssland började man på 1860-talet planera en reform av straffsystemet. Målet var att i enlighet med västerländska förebilder skapa ett system som täckte hela riket. Förvisningen ansågs vara ett i huvudsak olämpligt och gammalmodigt straff. Den blev dyr för staten och dess nytta var tvivelaktig. Man konstaterade likväl att ett förnyande av hela straffsystemet var en stor del och invecklad uppgift. Därför beslöt man att genomföra reformerna stegvis enligt en behovsordning. ${ }^{29}$

Det konkreta reformarbetet i Ryssland kom i gång år 1879 då man grundade en fängelsestyrelse under inrikesministeriet. ${ }^{30} \mathrm{I}$ sin strävan att minska förvisningarna tog fängelsestyrelsen kontakt också med Finland och föreslog att man skulle upphöra med deportation av finnar. Med stöd av prokuratorns och fångvårdsstyrelsens utlåtanden avskaffade den finska senaten förvisningen av sådana som dömts till långa fängelsestraff och av sådana, som fängslats för upprepat lösdriveri. Avskaffandet av deportationerna av dem, som dömts till dödsstraff, anknöts av senaten till ikraftträdandet av en ny strafflag. Dödsstraffet och samtidigt också förvisningen skulle försvinna $\mathrm{i}$ och med den nya strafflagen. ${ }^{31}$

Även i Ryssland planerade man en strafflagsreform, men före den blev färdig började man reformera förvisningssystemet. Finnarnas beslut att koppla samman ett fullständigt avskaffande av förvisningarna med strafflagsreformen tillfredsställde därför inte den ryska fängelsestyrelsen. Inrikesminister D. A. Tolstoi förfrågade sig hos ministerstatssekreteraren om förvisningarna inte kunde avskaffas före den nya strafflagen trädde i kraft. Då generalguvernör F. L. Heiden sände Tolstois skrivelse till senaten hänvisade han till brevväxlingen i ärendet och till de beslut som fattats. Han hade dessutom diskuterat med ministerstatssekreterare C. Ehrnrooth. Enligt denne kunde man upphöra med förvisningarna genast då de förordningar som gällde dem blev upphävda. Senaten förfrågade sig igen om (den finska) fångvårdsstyrelsens åsikt. Fångvårdsstyrelsen meddelade, att under de senaste åren hade nya fånglokaliteter blivit inrättade och att under den närmaste tiden skulle än mer lokaliteter färdigställas. Därför kunde de dödsdömda framdeles placeras i Finland. Senaten behandlade ärendet 7.5.1888. Med hänvisning till fångvårdsstyrelsens skrivelse underställde man kejsaren ett beslut, i vilket man föreslog att straffet för dem som deporterats till tvångsarbete, skulle omvandlas till livstids tukthus i Finland. Alexander III godkände underställningen 26.5./7.6.1888, och sålunda hade förvisningen till Sibirien avlägsnats ur Finlands straffsystem. ${ }^{32}$ 


\section{Frågan om benådning av de förvisade}

Deportationen av finländare upphörde vid en tidpunkt, då de finsknationella idéerna levde $\mathrm{i}$ en stark uppgångsperiod. Samtidigt var relationerna till Ryssland utmärkta. Under det följande decenniet skedde en förändring. Det rysknationella tänkesättet förstärktes i kejsardömet. Trycket mot minoritetsfolk och vissa särskilda områden växte. Finländarna skred till försvar av sina rättigheter genom att uttryckligen vädja till juridiska synpunkter. Alla de områden, där man ansåg det motiverat att försvara de finska intressena, drogs med i striden. Finländarnas möjligheter att försvara sina rättigheter förändrades också såtillvida, att man i Finland år 1907 övergick från en ståndsuppdelad lantdag till en genom allmän och lika rösträtt vald enkammarriksdag.

På 1908 års första lantdag framlade ledamot A. Lagerlöf ett petitionsförslag om att benåda samtliga ännu i livet varande finländare som hade förvisats till Sibirien och att återsända dem till Finland på statens bekostnad. Enligt förslaget hade förvisningen från första början varit en olaglig och skadlig åtgärd, som inte hade någonting att göra med humanism. Förslaget återspeglade också den rätt allmänna uppfattningen, enligt vilken förhållandena i Sibirien var sämre än i Finland. ${ }^{33}$

Riksdagens grundlagsutskott biföll petitionsförslaget, men $\mathrm{i}$ detta skede hamnade de till Sibirien förvisades ärende under viktigare politiska händelser. Lantdagens antipati mot senaten och Ryssland ledde nämligen till att riksdagen upplöstes. $^{34}$

Under följande lantdag, som samlades samma år, förnyade Lagerlöf sitt förslag, men inte heller nu hann man behandla det, förrän lantdagen igen

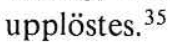

Tredje gången framlade Lagerlöf sitt förslag på 1909 års lantdag. De upprepade upplösningarna av folkrepresentationen förbättrade inte relationerna mellan Finland och Ryssland utan ledde till att lantdagen radikaliserades. $\mathrm{Nu}$ biföll lantdagen enhälligt Lagerlöfs förslag. Den ansåg att Sibirien-deportationen i alla avseenden hade varit en för fången skadlig åtgärd och att dẹn dessutom stridit mot Finlands grundlagsenliga rättigheter. ${ }^{36}$

Innan lantdagens beslut förelades kejsaren behandlade senaten grundigt benådningsfrågan. Senaten medgav, att förvisning inte ingick i Finlands lagstiftning, men ansåg att det endast hade varit frågan om tillämpning av den $\mathrm{i}$ lagen åt härskaren beviljade benådningsrätten. Enligt senaten fanns det inte heller fångvårdsmässiga grunder att återsända några deporterade som inte mera kunde anpassa sig i Finland. Senaten fick stöd för denna uppfattning från Sibirien av Johannes Granö, som inte godkände Lagerlöfs förslag. Att återsända finländarna skulle även ha varit emot Rysslands dåvarande Sibirien-politik. Regeringens målsättning var att flytta så många nybyggare som möjligt till 
Sibirien. Senaten föreslog för kejsaren att Lagerlöfs förslag måtte förkastas, och slutgiltigt avgjorde kejsaren ärendet genom att förkasta förslaget 25.7./7.8.1914..$^{37}$

Adresse: Dr. Alpo Juntunen

Historiska institutionen

Henriksgatan 2, SF-20500 Åbo 50

Artikeln baserar sig på författarens finskspråkiga doktorsavhandling om de finska Sibirien-deportationerna, »Suomalaisten karkottaminen Siperiaan autonomian aikana ja karkotetut Siperiassa«. Statistik, grafiska framställningar, fotografier och kartor har publicerats $\mathrm{i}$ avhandlingen.

2 E. Anners, Humanitet och rationalism. Lund 1965, s. 272-290; V. Virtanen, Suomen vankeinhoito I 1808-1831 (Finlands făngvård I 1808-1831). Helsinki 1944, s. $39-46$.

3 L. Schultz, Russische Rechtsgeschichte von den Anfängen bis zur Gegenwart einschliesslich des Rechts der Sowjetunion. Lahr 1951, s. 152; M. Raeff, Michael Speransky. Stateman of imperial Russia 1772-1832. The Hague 1957, s. 268-269.

4 Borgå lantdagshandlingar.

5 M. Calonius, Matthiae Calonii opera omnia. Appendix: Matthias Calonii svenska arbeten. Supplementband utgifvet av Theodor Sederholm. Helsingfors 1870. s. 352-357.

6 StS 66 71/1817. Forkortningen StS står för Ministerstatssekretariatets arkiv. Ministerstatssekretaren var Finlands representant hos den ryska Kejsaren i St. Petersburg.

7 A. Halila, Porvoon valtiopäivät ja autonomian alkuaika. Suomen kansanedustuslaitoksen historia I (Borgå lantdag och autonomins första tid. Finska folkrepresentationens historia I). Helsinki 1962, s. 552.

8 K. Korhonen, Suomen asiain komitea. Suomen korkeimman hallinnon järjestelyt ja toteuttaminen vuosina 1811-1826. (Komittén för finska ärenden. Organisationen och förverkligandet av den högsta administrationen i Finland åren 1811-1826). Helsinki 1963, s. 300-301.

9 Virtanen 1944 s. $387-390$.

10 Ukaz 29 128, 29129 P.S.Z. Sob. 1-e T 38, s. 433-487.

11 Korhonen 1963 s. 403-404.

12 Findlands Författningssamling 1826 s. 102-104; ukaz 275, 276 P.S.Z. Sob. 2-e T 1, s. $388-390$.

13 StS 3/1848; senatens akt KD 189/20 1847.

14 StS 188/1848; StS 189/1848; senatens justitiedepartement, protokoll 2.5. och 13.9.1848.

15 StS 69/1856; senatens plenarprotokoll 1.12.1856.

16 Prokuratorns berättelse 1882 .

17 R. Leijavuori, Lapsenmurhat Uudenmaan ja Hämeen lääneissä 1800-luvulla. (Barnamord i Nylands och Tavastehus län på 1800-talet). Pro gradu -arbete 1980, Helsingfors universitet s. 16, 26-30.

18 K. J. Ståhlberg, Irtolaisuus Suomen lain mukaan. (Lösdriveri enligt finsk lag). Helsinki 1893 , s. 22-49, 117-157.

19 Ukaz 29128.

20 Ukaz 19284 P.S.Z. Sob. 2-e T 20, s. 1010-1016.

21 De sibiriska deportationsmyndigheternas rapporter till justitiedepartementet vid Finlands senat 1845-1868; V. V. Gaupt, Sostojanije kolonii ssylnyh ljuteran. ispovedanija v Sušenskoi volosti, Minusin. okr. s 1850-1865 g. 2-ja Pamjatn kn. Jeniseisk. gub. na 1865 i 1866 g, s. 62-76; A. D. Kolesnikov, 0 natsionalnom sostave naselenija 
Omskoi oblasti. Istorits̀eskii protsess formirovanija naselenija Srednego Priirtyšja v etnits̀eskom i natsionalnom otnos̀enija. Materialy $\mathrm{k}$ tretjemu nautšnamy soveștśaniju geografov Sibiri i Dalnego Vostoka. Omsk 1966, s. 100-101.

22 Senatens ecklesiastikexpeditions akt KD 18/68 1864; StS 46/1866.

23 A. P. Salomon, Ssylka v Sibir. Otšerk jejo istorii i sovr. polożenija. S. Petersburg 1900 , s. $259-278$.

24 S. Patkanov, Statistits̀eskija dannyja pokazyvajus̀tšija plemennoi sostav naselenija Sibiri, jazyk i rody inorodtsev. Na osnovanii dannyh spetsialnoi razrabotki materiala perepisi 1897, g. I-III. S. Peterburg 1911-1912.

25 S. Maksimov, Sibir i katorga I. S. Peterburg 1891, s. 137-203; N. M. Jadrintsev, Sibir kak kolonija. S. Peterburg 1892, s. 272.

26 Litteraturblad 8/1860.

27 Senatens plenarprotokoll 24.4.1862.

28 V. Virtanen, Rangaistusjärjestelmän uudistus Suomessa 1800-luvun loppupuoliskolla (Reformen av straffsystemet i Finland under 1800-talets slut). Vankeinhoito 1938, s. 121-124; J. Laitinen, Vankeinhoidon voimavarojen kehitys 1860-luvulta nykypäivään. Suomen vankeinhoidon historiaa I (Utvecklingen av fångvårdens resurser från 1860-talet till våra dagar. Finlands fångvårds historia I). Helsinki 1981, s. $181-187$.

29 I. J. Foinitski, Uts̀enije o nakazanii v svjazi s tjurmovedenijem. S. Peterburg 1889, s. $317-318,435-436$.

30 Ukaz 59360 P.S.Z. Sob. 3-e T 1, s. 96-98.

31 Senatens akt KD 428/49 1886; StS 67/1887.

32 Senatens akt KD 165/17 1888; StS 49/1888.

331908 års lantdag. Petition nr 144.

34 U. Tuominen, Autonomian ajan yksikamarinen eduskunta 1907-1916. Suomen kansanedustuslaitoksen historia V. (Enkammarlantdagen under autonomin 19071916. Den finska folkrepresentationens historia V). Helsinki 1958, s. 188-189.

35 U. Tuominen 1958, s. 199-200.

361909 års lantdagsprotokoll 22.10. s. 521.

37 Senatens ekonomidepartement akt KD 370/38 1910; StS 94/1914. 